\title{
Up the nose of the beholder? Aesthetic perception in olfaction as a decision-making process
}

\author{
Ann-Sophie Barwich \\ Columbia University in the City of New York, Presidential Scholars in Society and Neuroscience, The Center for Science and Society, Fayerweather 511,1180 Amsterdam Ave.,
} New York, NY 10027, USA

\section{A B S T R A C T}

Is the sense of smell a source of aesthetic perception? Traditional philosophical aesthetics has centered on vision and audition but eliminated smell for its subjective and inherently affective character. This article dismantles the myth that olfaction is an unsophisticated sense. It makes a case for olfactory aesthetics by integrating recent insights in neuroscience with traditional expertise about flavor and fragrance assessment in perfumery and wine tasting. My analysis concerns the importance of observational refinement in aesthetic experience. I argue that the active engagement with stimulus features in perceptual processing shapes the phenomenological content, so much so that the perceptual structure of trained smelling varies significantly from naive smelling. In a second step, I interpret the processes that determine such perceptual refinement in the context of neural decision-making processes, and I end with a positive outlook on how research in neuroscience can be used to benefit philosophical aesthetics.

(C) 2016 Published by Elsevier Ltd.

\section{Introduction: aesthetic perception as observational refinement}

Is the sense of smell a subject for aesthetic theorizing? Orthodox ideas about aesthetics focus on visual and auditory objects, where philosophical interest in aesthetic values concerns the sophisticated structure of aesthetic experience (Carroll, 2001). These debates aim at a measure of objectivity for aesthetic judgment by asserting fathomable features in the objects of perception, such as harmony in music or proportion in paintings or sculptures. Olfaction has been almost univocally excluded in this context, in particular for its inherently affective nature. Odors are seen as lacking a sufficiently objective basis as well as a structural differentiation in their perceptual content that is required for their cognitive appraisal in an aesthetic sense. Nonetheless, the dismissal of smell in aesthetic studies is striking, especially given the rich history of olfactory and aromatic artifacts such as perfumes, whiskey, or wine (Classen, Howes, \& Synnott, 1994).

This article integrates the undervalued topic of odor perception into the general debate about aesthetics. The central point concerns the importance of refinement for aesthetic experience as an active engagement with stimulus features in perceptual processing. Drawing on olfaction, I argue that such refinement fundamentally shapes perceptual content, so much so that it sufficiently discerns the phenomenological structure of trained from naive smelling. In support of this claim, I bring together insights from two separate domains of work on olfaction. My analysis builds on recent research in sensory neuroscience, showing that smell is not a brutish sensation but subject to a range of cognitive processes (Shepherd, 2004, 2012). This scientific understanding is complemented with traditional knowledge about fragrance and flavor assessment in perfumery and wine tasting (Ellena, 2012; Smith, 2007a,b; Todd, 2010). By linking scientific with artisanal expertise this article aims to highlight the flexibility of percep- tual bias as the central element through which to investigate aesthetic experience in olfaction as an interactional process of observational refinement.

In a second step, I elaborate on the model of aesthetic experience as a refinement of perception by engaging with its empirical basis. Here, I offer an interpretation of the processes that determine such perceptual refinement in the context of decision-making mechanisms. Decision-making is a central component of perceptual processing and has received growing interest in research on the neural basis of cognitive processing (Gold \& Shadlen, 2007; Shadlen \& Kiani, 2013). It is fundamental to organismal behavior, and the underlying neural mechanisms operate at several levels to facilitate the discrimination of and attention to certain stimulus features. Decision-making, I suggest, allows for a more precise framing for the cognitive processing of selective attention that we see in aesthetic perception.

Overall, the article's purpose is twofold and divided into two thematic parts. The first part embeds olfaction in philosophical studies of aesthetic perception. The second parts builds on the first part's support from neuroscientific studies to offer a positive outlook on how research in neuroscience can be used to benefit philosophical aesthetics. More specifically, section 2.1 begins by identifying the reason for the dismissal of olfaction in aesthetics, namely its apparent lack of objectivity. Section 2.2 corrects the underlying misconceptions about odor perception by drawing on recent neuroscientific studies, further combining these scientific insights with traditional knowledge from perfumery and wine tasting. Section 2.3 analyzes the perceptual content of smell in terms of its aesthetic dimensions. The article then moves on to its second part and in section 3.1 frames the previously highlighted process of perceptual refinement with regard to studies of neural decision-making. Section 3.2 concludes by briefly addressing philosophical concerns about the use of neuroscientific studies for aesthetics in light of the emerging field of neuroaesthetics. 


\section{Part 1: Olfactory aesthetics}

\subsection{Can odors be an object of aesthetic theorizing?}

Can the sense of smell communicate aesthetic experiences? Tradition in aesthetic studies will have you believe that it cannot. What constitutes aesthetic perception is open to different perspectives. In essence, aesthetic experiences are considered to have a cognitive dimension in the sense that they are assumed to sharpen our rational access to the world through a sophisticated perception of particular features or objects (Carroll, 2001). Odors are not commonly thought of as representing the kind of sensory experience that admits of such cognitive value. This exclusion of smell from aesthetic theorizing draws on two convictions. First, olfaction is not considered to provide objective measures of its aesthetic qualities because the objects of odor perception are not accessible independently from their subjective perceptual experience. Rather, they are subject to individual judgment. Second, such individual judgment about smell perception does not offer a sufficiently objective basis or distinct phenomenological structure either. In light of this, the integration of olfaction into a discussion about the internal and external characteristics of aesthetic experiences is the first necessary step towards an understanding of the aesthetic dimension of smell.

To begin with, we must recognize that the strict opposition between objective and subjective experiences, which led to the general exclusion of smell from aesthetic studies, represents an older, intellectualized conceptualization of aesthetics. This conceptualization situates the grounds for aesthetic experiences as being external to the perceiver (e.g., to properties of objects), and the justification for such objectivism mirrors the domain in which most aesthetic debates are held. This domain is predominantly confined to the arts. Although, theoretically, objects of aesthetic experiences need not be objects of art (Mandoki, 2007; Saito, 2015), many considerations about what constitutes aesthetic perception derive from art studies (Carroll, 2001). Aesthetic perception in this context represents a particular form of cognitive appraisal underlying the judgment of art. Central to such judgment are the intellectual and potentially moral virtues of art, as found in David Hume's aesthetics. Occasionally, this view is associated with the idea that aesthetic appraisal is of a disinterested nature, that is lacking in self-interest and practical wanting. Here, we sometimes encounter the old assumption that beauty and reason must share a common cognitive and even normative dimension, and one of the most prominent and early advocates for this view was Immanuel Kant. ${ }^{1}$ On the whole, the underlying idea is that aesthetic experiences are intentional in the sense that they convey information about objects that is not bound to the individual's subjective perception. Thus, aesthetic experiences are about features of objects, not personal preferences.

From this perspective, smells do not present an obvious subject for aesthetic theorizing. According to philosophical introspection, odors do not account for objective properties of objects but appear primarily as individual experiences and somewhat instinctive. Some philosophers like Clare Batty (2010), therefore, refer to smells as mere phenomenological 'feels.' Moreover, smells do not seem to pos-

\footnotetext{
${ }^{1}$ Notably, Kant explicitly dismissed olfaction from yielding any positive value or benefitting from closer inspection: "Which organic sense is the most ungrateful and also seems the most dispensable? The sense of smell. It does not pay to cultivate it or to refine it at all in order to enjoy; for there are more disgusting objects than pleasant ones (especially in crowded places), and even when we come across something fragrant, the pleasure coming from the sense of smell is fleeting and transient." (Kant, 2006 [1798], pp. 50-51; italics in original).
}

sess sufficient cognitive content. Other philosophers, for example William Lycan (2000), consider smells to be poor in information because they lack clear spatial dimensions such as in visual perception (e.g., accounting for an object's position, orientation, or directness). For these and similar reasons, smell still stands in the reputation of being a lower sense that engages in "mere physical sensation - the mindless 'pleasures' of the body (Classen 2001)." It shares this fate together with the senses of touch and taste. In contrast with the 'higher senses' of vision and audition, which are seen as being closer to the faculty of reason, the so-called lower senses have thus been dismissed from aesthetic studies based on their appeal to animal instincts. Indeed:

"The devaluation of smell in the contemporary West is directly linked to the revaluation of the senses which took place during the eighteenth and nineteenth centuries. The philosophers and scientists of that period decided that, while sight was the pre-eminent sense of reason and civilization, smell was the sense of madness and savagery. In the course of human evolution, it was argued by Darwin, Freud and others, the sense of smell had been left behind and that of sight had taken priority. Modern humans who emphasized the importance of smell were therefore judged to be either insufficiently evolved savages, degenerate proletariat, or else aberrations: perverts, lunatics or idiots." (Classen et al., 1994, pp. 50-51; italies in original)

Is such dismissal justified? Contemporary views about the human sense of smell keep to similar sentiments. However, this understanding of olfaction rests more on misconceptions than facts. In fact, we have done research on the senses and perceptual experience a major disservice by neglecting the sense of smell, as the human sense of smell has not 'been left behind.' Neither is smell in evolutionary decline nor is it cognitively insignificant. To the contrary, its importance and processing have changed from orthonasal (inhaling) to retronasal (mouth breathing) olfaction, a process that is fundamental to our refined capacities in flavor perception (Shepherd, 2004, 2012). Our abilities in flavor discrimination and their appraisal are highly cultivated, and the development and varieties of human cuisine is one of the most central cultural achievements (Spence \& Piqueras-Fiszman, 2014).

The trade with fragrances and flavors has always been one of the most lucrative and influential constituents of human culture. Historically, the spice trade and the ongoing hunt for new flavors have shaped our modern socio-economic landscape (Freedman, 2007). From a contemporary point of view, we have become flooded with flavored and scented products and we find an entire industry occupied with selling fragrant and flavored products - quite successfully so. Today, 28 billion dollars are generated annually with fragrant products in the US alone, ranging from high-end perfume to scented trash bags (Keller \& Vosshall, 2004). From a pragmatist perspective, smell and flavor, regarding their creation as well as masking, are central elements of human culture (Classen et al., 1994; Gilbert, 2008).

Moreover, our vocabulary for smell and flavor experiences is not diminished either. Instead, this idea represents another misconception (notably, one that is often cited in support for the hypothesis about the evolutionary decline and cognitive deficiency of olfaction). As a recent series of psycholinguistic and anthropological studies has demonstrated, our limited vocabulary represents an artifact of (modern Western) cultural neglect, not a fact about human biology (Majid, 2016; Wnuk \& Majid, 2014).

Therefore, to understand how olfaction admits to aesthetic experience, we must revisit its biological basis, in particular its links to higher-level brain processing, in parallel with the perceptual expertise 
that is involved in the assessment of fragrances and flavors. The following section will use these insights to reevaluate the strict distinction between perception and cognition, and to pave the way for an objectivist stance on odor perception.

\subsection{Cognitive penetration in odor perception: insights from neuroscience}

How are smells processed, to which external features of objects does odor perception relate, and can they communicate aesthetic experience? The process of smelling is an interpretation of chemical information in the environment through our sensory system. Our nose detects volatile airborne molecules and our brain makes sense of their information by turning them into smells. How does the brain make sense of scents? The central organ of olfactory experience is indeed not the nose but the brain. This insight is fairly recent, as research on smell became part of mainstream sensory neuroscience only after the discovery of the mammalian olfactory receptors by Linda Buck and Richard Axel in 1991. That said, comprehensive scientific understanding of the organizational principles underlying higher-level brain processing in olfaction presents an open issue to date. In particular, the cortical representation of odor stimuli remains unresolved. Nonetheless, over the past 25 years, vast progress has been made in modeling the olfactory pathway and tracing olfactory signaling (Axel, 2005; Barwich, 2015; Firestein, 2001; Shepherd, 2006). A central realization in this context is that olfaction involves a significant amount of top-down processing (Chen et al., 2014; Zelano, Mohanty, \& Gottfried, 2011).

These insights prove essential for philosophical interest in the aesthetic dimensions of odors, as it corrects the long-standing assumption that olfaction is a brutish sensation that lacks cognitive load and sophistication. This opinion constituted the principal reason for the exclusion of the sense of smell in aesthetic studies. Smells were judged as unsuitable for aesthetic theorizing because they were considered as being too subjective, meaning (i) they do not exhibit a sufficiently cognitive dimension but represent mere feels and (ii) they are not intentional (about objects) but expressed only personal preferences. Noticeably, this opinion is based on a strong conceptual division between perception and cognition, a division that is a result of a predominantly visuo-centric approach. Drawing on recent advances in olfactory neuroscience, the strict distinction between perception and cognition has been challenged by a number of recent philosophical works, however (Barwich, 2016, Barwich, 2017; Keller, 2017b). Besides, even in philosophical analysis of vision this distinction has become subject to much scrutiny, for example in recent debates about cognitive penetration (Burnston, 2016; Macpherson, 2012).

In comparison to vision, judgment about odors is even more deeply entwined with their perception (Keller, 2017a). A variety of top-down processes and cognitive penetration inevitably shape odor perception. Next to recordings of neural top-down feedback from higher cortical areas (Chen et al., 2014), such effects are also well-known phenomena in psychophysical research. For example, a study by Herz and von Clef (2001) investigated the effect of verbal labeling on smell perception. Here, subjects were asked to sniff pairs of mixtures, which, unbeknownst to them, had the same chemical composition but were given different evaluative names (such as "musty basement" and "incense" for Patchouli). The majority of subjects (83\%) could distinguish the mixtures and further attributed different hedonic tones (i.e., pleasant or unpleasant) to them. Similar effects were observed regarding the influence of visual clues on odor (Zellner \& Kautz, 1990). What these results suggest is that the division between sensory and cognitive processing is not as strict as previously be- lieved. Dismissal of scent in aesthetics on such grounds is, therefore, no longer apt.

Such insight about the influence of top-down processes on olfaction resonates strongly with the traditional knowledge of experts in artisanal contexts. Ignored by intellectualized aesthetic debates for centuries, wine tasters and perfumers have developed considerable analytical skills and techniques for conceptually breaking down fragrances (orthonasal) and fragrances (retronasal smell) into their individual perceptual notes and components. These skills often attracted mockery and accusations of snobbery, not least because of their sometimes excessively flamboyant style of descriptions: "when I find someone I respect writing about an edgy, nervous wine that dithered in the glass, I cringe. When I hear someone that I don't respect talk about an austere, unforgiving wine, I turn a bit austere and unforgiving myself ... You can call a wine red, and dry, and strong and pleasant. After that, watch out ... ! (Kingsley Amis as quoted in Shapin, 2012, p. 51)"

Moving beyond the stigma of pretentious writing, scientific studies have shown that wine and perfume experts really exhibit better discriminatory abilities when it comes to distinguishing, memorizing, and verbally characterizing fragrances and flavors (Croijmans \& Majid, 2016; Melcher \& Schooler, 1996; Zucco, Carassai, Baroni, \& Stevenson, 2011). Their heightened abilities are not due to some super-perceptual powers of individuals but, rather, based on an extensive verbal and perceptual training that experts have diligently undertaken over several years. Laypeople can acquire and exhibit increased perceptual skills even after a few weeks' training also. More recent research on the role of expertise in olfaction further elicited the underlying effects of such training in terms of functional and structural modifications in the neural processing of odors (for a review about the impact of expertise in olfaction, see Royet, Plailly, Saive, Veyrac, \& Delon-Martin, 2013). On this account, the expertise of wine tasters and perfumers constitutes a form of trained and specialized perception that builds on the same neural processes as normal perception. In turn, our investigation of aesthetic perception in olfaction has changed: We must not ask any longer whether olfaction can communicate aesthetic experience, but when and under what conditions.

\subsection{The structure of olfactory perception and its aesthetic dimensions}

What is the structure of olfactory and, in particular, aesthetic olfactory experience? Smell appears to present the perceiver with an immediate sensation of a unified percept. When you inhale a perfume or drink fine wine, you perceive their qualities as an undifferentiated synthetic whole at first. This understanding of odor and flavor has led to the widespread opinion that olfactory percepts do not seem to possess any clear perceptual structure or cognitively assessable content. Such an impression, however, only accounts for naive smelling. By contrast, trained and analytic smelling or tasting attends to the perceptual properties. It is an active, not a passive form of perceiving. Here, perceptual properties are deliberately sought out, discriminated, compared, judged, and linked to previous experiences. From this view, the naive smeller and the analytic one perceive differently because they are engaging in different processes. Unlike the untrained perceiver, the discriminatory abilities of experienced smellers are guided through attention and directed focus, shaped by the yearlong experience of decomposing odor and flavor notes (a similar argument has been made for tasting, see Smith, 2007a,b; Todd, 2010).

For this reason, the content of perception is not defined solely by what is presented immediately to us through the senses. Perceptions can be refined. Refined perceptions are governed by a variety of top-down processes, such as experience, memory, attention, expectation, 
and intention. They are further penetrated by cognitive influences through education, knowledge, imagination, and culture. In particular aesthetic experience is conceived as constituting such a refinement of perception by providing a cultivated apprehension of particular features of experience and objects. Such cultivation of perception is not only a capacity of the visual and auditory but also of the gustatory and olfactory systems. Our perceptions of scent and flavor can be broken down into different components and temporal sequences, some of which require refined cognitive access for their evaluation (Ellena, 2012).

To be sure, smell is very difficult to measure and define. Its cognitive dimension is strongly influenced by contextual and subjective factors such as associations and memories (Barwich, 2014). Moreover, many biological factors such as genetic differences across individuals lead to varying perceptual capacities (Keller \& Vosshall, 2008). Psychophysical measurement differentiates between four different aspects of smelling: threshold (i.e., the detection of odors at low concentrations); intensity (i.e., the strength of an odor sensation); persistence (i.e., the duration of an odor sensation); hedonic tone (i.e., the pleasantness and affect of an odor sensation); and character descriptions (i.e., the perceptual quality of an odor sensation) (Barwich \& Chang, 2015; Hummel \& Welge-Luessen, 2006; Wise, Olsson, \& Cain, 2000). For our consideration about olfactory aesthetics, we will be concerned with odor quality and hedonic tone only.

Conceptualizing odor quality is a daunting task. Odors seem to come in general classes (e.g., garlicky, burnt, floral, green), yet their number is almost endless (e.g., violet, iris, lily, etc.). Unlike for the visual or auditory system, the physical stimulus of smell has not led to a comprehensive classification yet. However, this is not a result of the seemingly subjective nature of smells but the physical characteristics of the olfactory stimulus. Instead of being based on a single, linear parameter such as wavelength, the molecular basis of smell is non-spatial but multidimensional (Keller \& Vosshall, 2016; Ohloff, Pickenhagen, \& Kraft, 2011).

Nonetheless, perfumers, wine tasters, and other fragrance or flavor experts have developed a variety of classifications to deal with the inherent qualitative complexity of smells. These classifications are often presented in so-called fragrance or aroma wheels. In comparison, these wheels can vary both in their constitutive classes and ordering criteria. That said, they all build on a similar functional premise. Using mainly vernacular terms, the purpose of fragrance and aroma wheels is to provide a standard terminology for the communication between perfume or wine creators, consumers, and retailers.

Influential examples for such wheels are, for example, the wine aroma wheel by Ann C. Noble or the fragrance wheels by Ulrich Harder and Michael Edwards. Resting on basic, well-known odor groups (plus subgroups), these classifications guide the qualitative characterization of wine or perfume. For example, in Harder's wheel, we find floral odors divided into three abstract sensory categories, namely 'light,' 'green,' and 'heavy.' These categories are further surrounded by seventeen more specific notes. Notably, "the circle is arranged in such a way that related notes are adjacent and blend seamlessly with one another (Ohloff et al., 2011, p. 31)." In comparison, the wheel of Michael Edwards (Fig. 1) addresses a broader range of qualities, namely 'floral,' 'oriental,' 'woody,' 'fresh,' and 'fougère.' These classes are also divided into subgroups, such as 'dry woods,' or 'mossy woods.' An interesting feature of this representation is its dynamic character: apart from 'fougère,' all categories can be rotated to combine the outer dimensions of odor quality and the inner dimensions of sensual impressions in the classification of a specific odorant.

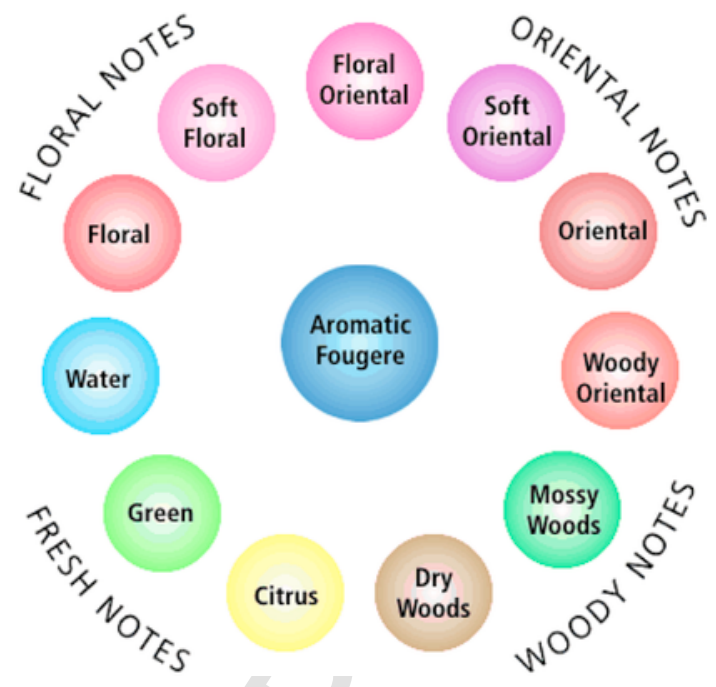

Fig. 1. Fragrance wheel of Michael Edwards (image by Epaun, 2007): Edward's wheel was originally designed in 1983 but modified several times since.

Qualitative categorization constitutes a necessary but not sufficient element in training the aesthetic appraisal of odors or flavors. Categorization is not primarily an aesthetic activity. Regarding the aesthetic assessment of wines or perfumes, these wheels thus represent only one dimension. Another important dimension is hedonic tone, which refers to the affective nature of smells as being pleasant or unpleasant. Current research in olfaction investigates the correlation of odor qualities and hedonic tone by modeling so-called sensory maps (Zarzo $\&$ Stanton, 2009). Such sensory maps aim at a systematic representation of odors that correlate some perceptible features of the physical stimuli with topographically organized activation patterns in the brain (Fig. 2). The dimensions of hedonicity in these maps are interpreted along two axes with opposite poles. These poles describe four key effects: (i) erogenous and anti-erogenous, and (ii) narcotic and stimulating. The arrangement of odors under these criteria does, however, not always result in clear-cut cases. Often, such classes exhibit a hybrid character: "narcotic plus anti-erogenous is calming; anti-erogenous plus stimulating is fresh; stimulating plus erogenous is exalting; erogenous plus narcotic is sultry (Donna, 2009, p. 28)."

Thus, when we take a look at the content of aesthetic judgments about perfumes or wine, we must distinguish between different dimensions as constituting their aesthetic perception. Resonating with the above categories of psychophysical measurement, we find similar levels of perceptual analysis represented in wine and perfume assessments. First, there is the descriptive level of qualitative characterization, which we saw in the aforementioned fragrance and flavor wheels. Then, there also is the evaluative part of the examination. Here, evaluations can refer to objective assessments of qualitative differences (i.e., whether the odor notes in a perfume or wine are well-balanced or a note is too intense). Yet, they could also express personal preference (e.g., I might intellectually appreciate the harmony of odor notes in a particular perfume or wine, but that will not necessarily compel me to like it). Also, reflecting our verbal and cultural associations, we are often confronted with a mixture of literal and metaphorical expressions in aesthetic assessment (Todd, 2010, p. 48). From this perspective, judgments about aesthetic experience tend to blend analytical with associative apprehension in perceptual processing.

Let me follow up with some illustrative examples about perfume. Consider the following assessment of the fragrance Parure (intro- 


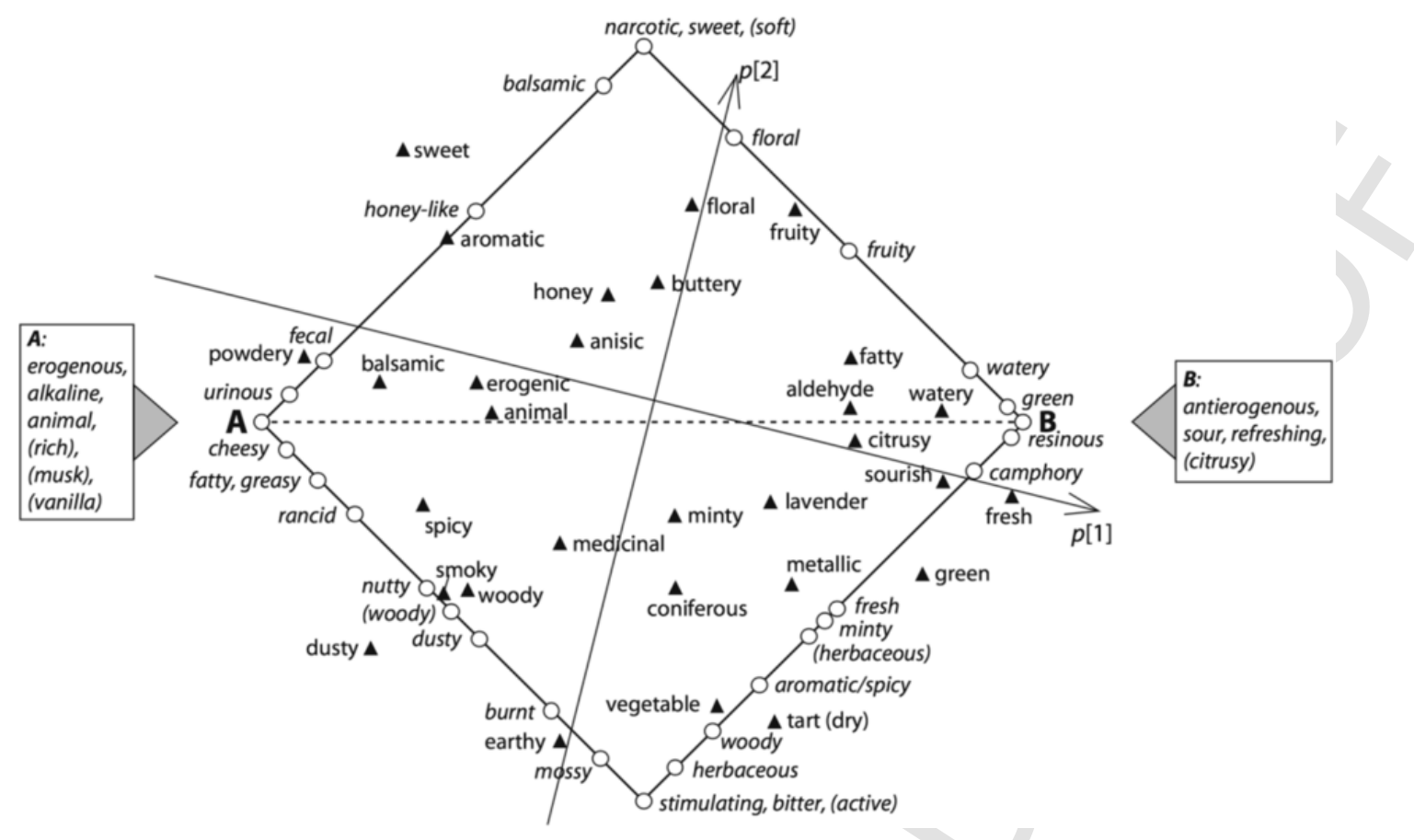

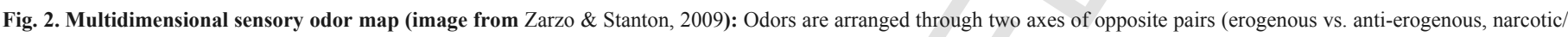

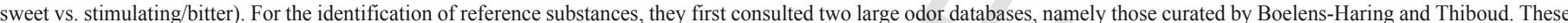

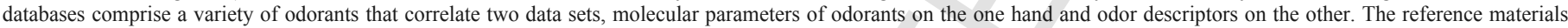
these contain were then scaled and compared with Paul Jellinek's influential odor effects diagram (Jellinek, 1997).

duced by the company of Guerlain in 1975):

"The citrus and galbanum in Parure ('Jewelry Set') is bracing and bitter. Herbal notes of thyme and clary sage soften this brightness and prepare you for the sweet warmth of a jasmine that shines like the sun within Parure's dry mossy, leather impression. Soon enough, the 'formal' part of the perfume announces itself: leather, moss, styrax, and vetiver, with amber and Tolu balsam's warmth echoing the jasmine. For a moment, there is an interesting caramel note that recalls Azurée and Miss Balmain, an evanescent gourmand quality in an otherwise fresh and mossy-dry fragrance. Parure's balance of citrus, warmth, and mossy-dry-leather is perfection." (Herman, 2013, p. 152)

We encounter several levels in the aesthetic assessment of Parure. The quote mainly focuses on the temporal structure and the development the perfume: starting with a top note (citrus, galbanum, galbanum, clary sage), proceeding to the heart note (jasmine), and revealing a base note (leather, vetiver, moss, amber). This elementary analysis is complemented by reference to the composition of the perfume as indicative of its quality (e.g., its balance, but also the interplay of complementary elements such as the caramel note in an otherwise fresh fragrance). Furthermore, fragrances with similar qualities are mentioned to situate the perfume's overall character in a tradition of similar fragrances. In addition to such a descriptive assessment, we can find more metaphorical descriptions of perfume, too: "If you've ever hiked near the mountains, you know what it's like to feel as if you're in multiple climates at once (Herman, 2013, pp. 74, on Alpona by Caron from 1939). Such associative characterizations can likewise reveal aesthetic impressions, in this case of the multiple levels of a perfume's composition. Sometimes, perfumes are evaluated in the context changing cultural or historical styles: "A simple, herbal/anisic chypre that Edmond Roudnitska described at the time as 'the only true chypre on the market' To a modern nose, it might come across a little too lemony (Herman, 2013, pp. 101, on Eau Fraîche by Christian Dior from 1953)." Last but not least, many perfumes have a strong hedonic dimension that permeates their experience: "With the narcotic sweetness of neroli, ylang-ylang, and jasmine, initially pushed in a green, fresh direction by its sharp top notes, My Sin quickly drops it like it's hot in the base notes, with a lascivious and warm civet-led balsamic drydown (Herman, 2013, pp. 38, on My Sin by Lanvin from 1924)." - It is worth pointing out that flavor and taste properties in wine are analyzed in a similar fashion (Smith, 2007a,b; Todd, 2010).

We have now arrived at a perspective on olfactory perception that reveals its content and structure as being formed by several perceptual layers and evaluative dimensions. If we understand aesthetic perception as providing a refined and attentive access to special features of objects and sophisticated experience, then olfaction certainly admits to such appreciation. What can we conclude from this understanding of olfaction for the general debate about aesthetic perception? Throughout this paper, I combined recent insights from neuroscience with traditional knowledge in perfumery and wine tasting to integrate olfaction into the philosophical discussion of aesthetics. Here, we discovered two interrelated issues. First, the exclusion of olfaction in aesthetic discourse rests on a doctrine of objectivity that was rendered problematic. This doctrine entails an outdated separation of perception and cognition that stands in conflict with current understanding of neural feedback processes in neuroscience. Second, olfaction draws on a range of top down processes and is not, as previously assumed, a mere brutish sensation that lacks cognitive load. To the contrary, according to olfactory science, a variety of top-down processes such as expectation, attention and training fundamentally shape not only the identification of smell qualities but also their hedonic evaluation.

In further consequence, what we must recognize is that the perceptual expression of odor preferences is not necessarily given or 
fixed but leaves sufficient room for contextual evaluation and the individual acquisition of a differentiated range of tastes. With the exceptions of some intrinsically repugnant smells (e.g., cadaverine or skatole), odors can also represent acquired perceptions. As such, any evaluation of their content is a matter of exposure, experience, content, and training. This is not unlike the training in and the detection of styles in other sensory aesthetics. The important insight to take away from this is that the contextuality of odor evaluation does not mean that smell experience is merely subjective. A lot of the variability in smell experience is a result of contextual cognitive confluences and ascribes to the deep entrenchment of perception and perceptual judgment in olfaction. As we have seen here, humans have a strong capacity for analytic odor perception and evaluation, which points to the central cognitive element that characterizes general aesthetic experience. This element refers to the refinement of perception in order to recognize, discriminate, and evaluate the variable qualitative features of things.

\section{Part 2: Neuroaesthetics}

\subsection{Refined perception as a (neural) decision-making process}

I now want to elaborate on the model of aesthetic experience as a refinement of perception and engage with its empirical basis. The most important insight from the previous analysis on olfaction is that the processing that gives rise to aesthetic experiences differs substantially between naïve and trained smellers. This fact is by no means trivial but, as we come to explore in what follows, indicates a promising intersection of philosophical aesthetics with studies in neuroscience. As neuroscience sets out to unravel the brain mechanisms that constitute perceptual and cognitive processes, having also rectified our misconceptions about olfaction, it is reasonable to consider what it may contribute to the philosophical study of concepts such as aesthetic perception.

Empirical works in aesthetics already acknowledge that there are some differences between trained and untrained perceptual experience. One example for this is the appreciation of quality in artworks. Here, studies largely focus on a binary scaling of artworks between experts and laymen (e.g., the absence of craftsmanship versus craftsmanship; poor quality versus good quality) (Hekkert \& Van Wieringen, 1996). However, what has not been investigated thus far are the phenomenological differences in perceptual content and structure between naïve and trained perceivers. As argued throughout the previous sections, the phenomenological structure of refined aesthetic experience can vary quite significantly from naïve smelling in olfaction.

From a theoretical perspective, the process of refining perceptions implies the capacity of reshaping our current perceptual constraints. Such reshaping concerns the reinterpretation of the available perceptual options through selective attention. What this means more concretely is that particular stimulus features are initially identified and classified (as belonging to a kind of perceptual objects) to be further discriminated through a comparison with similar elements known from previous experience and training. This comparison then allows weighing these elements regarding the standards of their perceptual class. Such measures can be broadly conceived (e.g., how is X as a white wine) and also further specified (e.g., how is X as a Riesling, or how is $\mathrm{X}$ as a Riesling from this location or that year). As a result of such refinement of a perception, aesthetic experiences mirror an iterative cognitive engagement with a perceptual process. In this context, our anticipations regarding the nature of the stimulus and its features can enhance or distort the evaluative processing. This model of re- fined processing illustrates that aesthetic perception exceeds an immediate impression of mere liking a thing (though it does not exclude it).

In experimental studies of aesthetics, the elements of such comparisons in perceptual refinement have been referred to as "collative properties" (Berlyne, 1971). A similar, more detailed, description is given by Walton (1970) in philosophical aesthetics. Aesthetic processing of properties in this context refers to three kinds of perceptual evaluations, namely standard or stereotypical, variable, and contra-standard features of perceptual elements. So, for example, a Riesling might be evaluated as being 'dry' (standard), as having the qualities of 'apple' or 'petrol' (variable, depending on the grape region and the wine's age), and as having 'high alcohol content' (contra-standard, e.g., in the French version Riesling D'Alsace).

Modeling the cognitive processing of such comparative evaluations in the refinement of perception is precisely where insights from neuroscience may complement and further general aesthetic debate in the near future. In particular studies of decision-making are relevant in this context. Scientific interest in the neural basis of decision-making has been thriving, especially over the past 25 years. It deeply connects research from neuroscience with works in economics, psychology, computational science, cognitive science, and philosophy. ${ }^{2}$ In essence, research on decision-making investigates the neural mechanisms of weighing and selecting with respect to the presence and shifting dominance of perceptual cues. Decision-making refers to various unconscious as well as conscious processes that select between incoming signals based on several, sometimes conflicting decision factors in relation to a range of appropriate responses (e.g., Gold \& Shadlen, 2007; Shadlen \& Kiani, 2013). ${ }^{3}$

My impression of the shared, though implicit, interest between studies of aesthetic perception and neural decision-making is reflected in the questions that are driving decision-making research, such as: How does our brain act and decide that a particular constraint for weighing and comparing a perceptual element is inadequate, thereby readjusting the perceptual sensitivities? How can sets of diagnostic cues (e.g., cross-sensory, verbal labeling, etc.) shift our attention and, in turn, affect and form our perceptual structure and qualitative experience (such as in wine tasting)? Decision-making expresses and even requires a certain flexibility and changeability in perceptual attention and selectivity.

\footnotetext{
${ }^{4}$ What, for instance, makes an input strong enough for our brain to act on it? In the case of olfaction, we are constantly surrounded by hundreds of odorous molecules, but we rarely are aware of their smell. Slightest concentration changes in our chemical environment can change such obliviousness immediately, however. Likewise, you may not wake up from the traffic outside your window, but a screaming baby will alert you right away. Perceptual processes investigated from the perspective of decision-making processes thus relate to the selectivity by which organisms engage with their environment. For some neuroscientists, decision-making, therefore, even constitutes the foundation for perception and cognition (Gold \& Shadlen, 2007).

${ }^{3}$ In this context, decision are generally defined as "a commitment to a proposition or plan of action based on information and values associated with the possible outcomes" and the study of decision making in current neuroscience focuses on "the discovery of neural mechanisms that support accuracy, speed, and confidence in a decision" (Shadlen \& Kiani, 2013).

2 That said, research on decision-making has not been directly linked to any questions surrounding philosophical aesthetics yet. Notwithstanding, with respect to the here outlined refinement model of aesthetic perception, I think that it yields a great potential to further our understanding of perceptual refinement. This claim is validated not at least by research tendencies in the industry, where an increase of neuroimaging studies is supposed to shed light on the perceptual cues and processes that influence consumer decision-making (Ariely \& Berns, 2010).
} 
Refined perception significantly builds on such selective attention in decision-making processes and, in turn, is deeply context-dependent in its nature (flexibility of diagnostic cues). In refined perception, we conceived something as aesthetic because we experience it as being somewhat comparable yet different and preferable to other, similar enough elements. The inherent potential for the sophistication of our senses through the flexibility of selective attention, is fundamental to perception in general and aesthetic perception in particular. What we experience through aesthetic perception is selective on a signal's combination with other sensory cues, previous experiences, and our capacity to shift attention to particular qualitative features of the perceptual object.

The upshot is that aesthetic perception represents a cultivation of preferences regarding specific features of the environment and particular stimulus features. While you may be unable to perceive certain features due to lack of training and awareness, a fragrance expert will easily be able to point you at subtle differences in the composition of a complex mixture, relating to the harmony and proportions of its ingredients. Therefore, the perception of odors and their aesthetic value is not a subjective sensation, as it was claimed in pervious philosophical debate. Smell is objective in the sense that it concerns an evaluation of salient stimulus features. Objectivity does not imply that smell is not invariant, as it is subject to observational training, selective attention, and contextual cues. Moreover, the effects can be studied both with respect to the phenomenological structure of their perceptual experience as well as their neural correlates.

\subsection{Outlook: aesthetic theorizing in the age of neuroscience}

In closing, I briefly want to reflect on the implications of consulting neuroscience in philosophical debates on aesthetics. Over the past two decades, it has become reasonable to wonder whether we must think differently about aesthetic perception in the time of neuroscientific breakthroughs. A considerable part of my argument for rehabilitating the sense of smell from oblivion in philosophical aesthetics was drawing on recent insights from sensory neuroscience. By extension, I further interpreted the emphasized refinement of perception through its neural foundation as a decision-making process.

Such a neuro-centric approach mirrors a current trend in cognitive neuroscience. A recent approach that ventures into the underexplored biological basis of aesthetic experience is the emerging field of "neuroaesthetics." Neuroaesthetics, a term introduced by Zeki and Nash (1999), refers to a growing domain in cognitive neuroscience, where researchers hope to identify and understand the neural basis of aesthetic perception by looking at brain activation patterns during the perception of art ${ }^{5}$ However, the use of neuroscientific studies in the analysis of traditionally philosophical concepts is not uncontested. Critics targeting the idea of modeling aesthetic experience through neural processes have pointed at the underdeveloped theoretical understanding of the aesthetic and art in many of these studies (Gopnik,

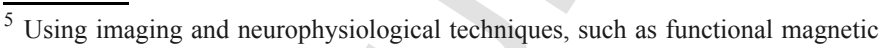
resonance (fMRI), magnetoencephalography (MEG) and electroencephalography (EEG), findings have highlighted the strong involvement of sensorimotor areas, core emotional and reward-related centers in aesthetic experiences (Chatterjee \& Vartanian, 2014; Chatterjee, 2011, 2013; Cinzia \& Vittorio, 2009).
}

2012). ${ }^{6}$ A central concern of philosophers here is that aesthetic experiences are considered to have a cognitive dimension that is not reducible to neural processing. This is a valid concern, but there is another way to envisage neuroaesthetics.

Neuroscience does not necessarily entail reductionism in the sense that all cognitive processes can be mapped neatly onto a neural correlate. Rather than explain away abstract concepts or phenomenological experiences, insights from neuroscience can enhance theoretical conception of ourselves as being capable of phenomena such as aesthetic perception. Some of the neural mechanisms that facilitate perceptual and cognitive processing point to features that distinguish different kinds of experiences. Therefore, I view neuroscience not as a tool to diminish the complexity of concepts such as aesthetic perception but, to the contrary, as a tool that allows us to dig deeper into its characteristics and specifics. Noticeably, the implementation of neuroscience does not force a specific philosophical position but its insights into the principles of higher brain organization can resonate with several philosophical ideas about aesthetic perception in contemporary discourse. When we compare the positions in the philosophical debate with studies in neuroaesthetics in broad brushstrokes, we can find sufficient and instructive correspondences across different models of aesthetics experience to conceive of fruitful cross-links between the two different disciplinary approaches (Fig. 3).

In light of this, neuroaesthetics opens up a brand new domain of inquiry that has yet to define its concrete aims and principles. The shared aim, then, should be to formulate a naturalistic framework, which integrates the scientific expertise of sensory and cognitive processes with insight from the humanities about the contents and contexts of aesthetic experiences and interactions with artifacts. ${ }^{7}$ On this account, neuroaesthetics presents us with an excellent opportunity to make philosophical ideas relevant to ongoing experimental practice and, vice versa, using its findings to further the discussion of concepts in traditional aesthetic studies. The integration of smell into aesthetic debate through the integration of olfactory neuroscience with olfactory craftsmanship presented an example in this context.

\section{Acknowledgements}

I would like to thank Christine Hauskeller, David Barack, Andrew Goldman, and an anonymous reviewer for their helpful comments on earlier versions of the argument. The research for this article was made possible through generous funding from the Presidential Schol-

\footnotetext{
$\overline{7}$ Xenakis and Arnellos (2014) have made a similar call for a naturalistic approach to aesthetics.

${ }^{6}$ Especially scholars from the humanities have lamented the explicit failure of cognitive scientists to keep up and engage with contemporary art criticism and theories: "Surveying the literature of aesthetic science, it is striking how much of it depends on notions of art that date back decades, or even centuries, and that haven't been in play among experienced viewers for almost as long (Gopnik, 2012, p. 130)." That said, such negligence does not negate the need for a stronger integration of scientific studies on perception into aesthetic discourse: as "[i]t is an admittedly distressing fact that, for years, art historians and critics have ignored what experts on vision and the psychology of representation have discovered about the scenes artworks can show, and how they can show them (Gopnik, 2012, pp. 130-131)."'Moreover, as other critics have pointed out, neuroaesthetics also suffers from some of the same limitations as orthodox aesthetics. The majority of studies defines aesthetic experiences primarily in terms of art works and limits their experiments not only to visual art but specifically to paintings (Zaidel, 2015). Lately, though, a number of studies began to target other artistic modalities such as music, literature, and dance in order to develop a more general model of neuroaesthetics (Marin, 2015). That said, the chemical senses of smell and taste are yet again missing from this list of aesthetic modalities
} 


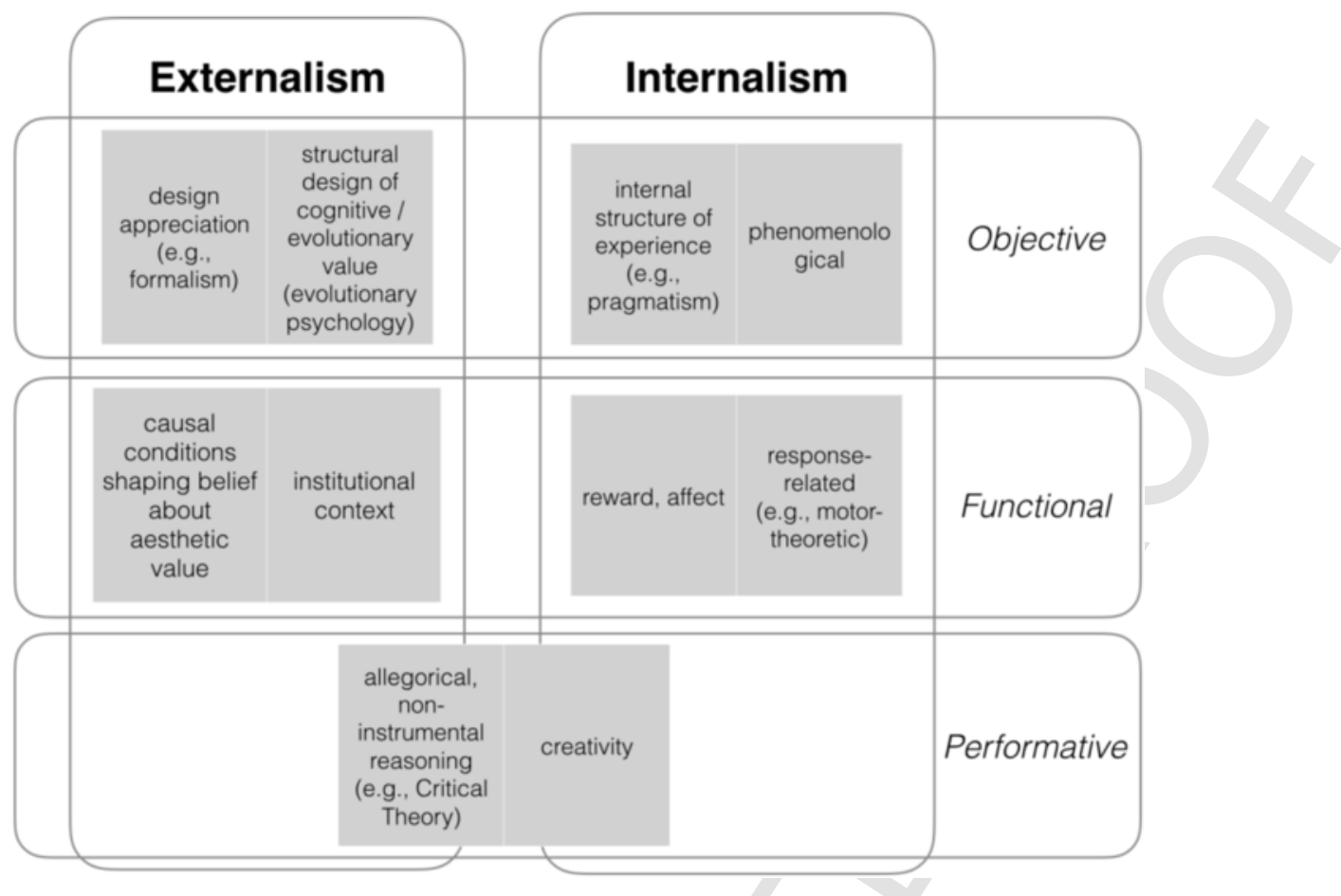

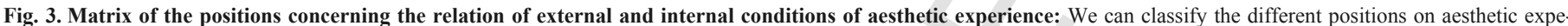

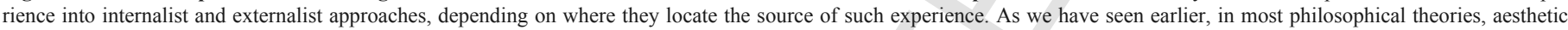

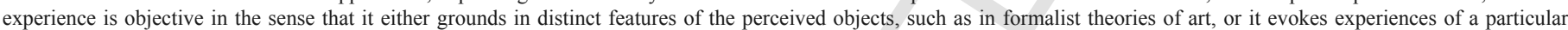

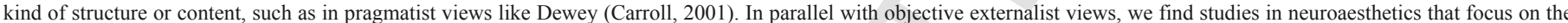

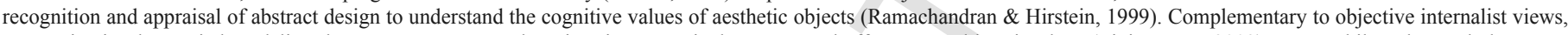

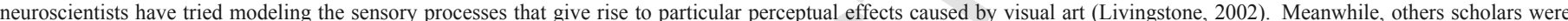

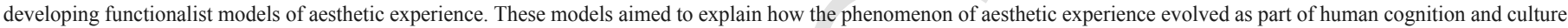

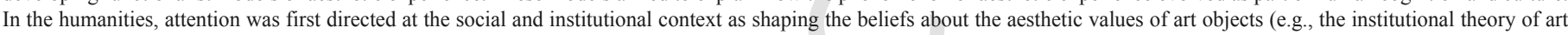

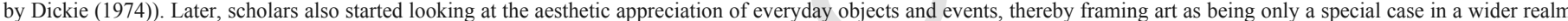

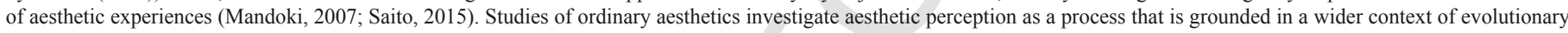

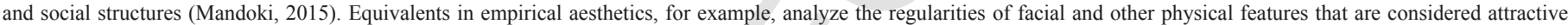

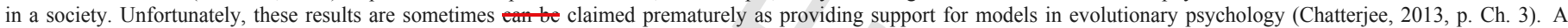

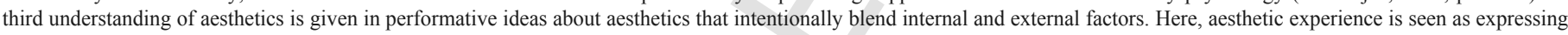

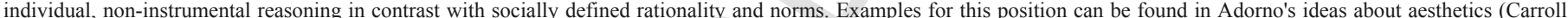

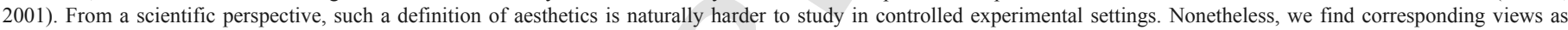
anecdotal reports of artistic creativity on brain-damaged patients (Chatterjee, 2011).

ars of Society and Neuroscience Program at the Center for Science and Society, Columbia University.

\section{References}

Ariely, D., Berns, G.S., 2010. Neuromarketing: The hope and hype of neuroimaging in business. Nature Reviews Neuroscience 11, 284-292.

Axel, R., 2005. Scents and sensibility: A molecular logic of olfactory perception (Nobel lecture). Angewandte Chemie International Edition 44, 6110-6127.

Barwich, A.-S., 2014. A sense so rare: Measuring olfactory experiences and making a case for a process perspective on sensory perception. Biological Theory $9,258-268$

Barwich, A.-S., 2015. What is so special about smell? Olfaction as a model system in neurobiology. Postgraduate Medical Journal 92, 27-33.

Barwich, A.-S., 2016. Making sense of smell. The Philosophers' Magazine 41-47.

Barwich, A.-S., 2017. Measuring the World: Towards a process model of perception. In: Nicholson, D., Dupré, J. (Eds.), Everything Flows: Towards a processual philosophy of biology. Oxford University Press, Oxford (in press).

Barwich, A.-S., Chang, H., 2015. Sensory Measurements: Coordination and standardization. Biological Theory 1-12.

Berlyne, D.E., 1971. Aesthetics and psychobiology, Vol. 336. Appleton-Century-Crofts, New York.

Burnston, D.C., 2016. Cognitive penetration and the cognition-perception interface. Synthese 1-24.

Carroll, N., 2001. Beyond Aesthetics: Philosophical essays. Cambridge University Press, Cambridge.
Chatterjee, A., 2011. Neuroaesthetics: A coming of age story. Journal of Cognitive Neuroscience 23, 53-62.

Chatterjee, A., 2013. The aesthetic brain: How we evolved to desire beauty and enjoy art. Oxford University Press.

Chatterjee, A., Vartanian, O., 2014. Neuroaesthetics. Trends in Cognitive Sciences 18, 370-375.

Chen, C.-F.F., Zou, D.-J., Altomare, C.G., Xu, L., Greer, C.A., Firestein, S.J., 2014. Nonsensory target-dependent organization of piriform cortex. Proceedings of the National Academy of Sciences 111, 16931-16936.

Cinzia, D.D., Vittorio, G., 2009. Neuroaesthetics: A review. Current Opinion in Neurobiology 19, 682-687.

Classen, C., Howes, D., Synnott, A., 1994. Aroma: The cultural history of smell. Routedge, London.

Croijmans, I., Majid, A., 2016. Not all flavor expertise is equal: The language of wine and coffee experts. PloS One 11, e0155845.

Dickie, G., 1974. Art and the Aesthetic: An institutional analysis. Cornell University Press, Cornell

Donna, L., 2009. Fragrance Perception: Is everything relative. Perfumer \& Flavorist $34,26-35$.

Ellena, J.-C., 2012. The diary of a nose: A year in the life of a parfumeur. Penguin UK.

Epaun, 2007. Wikipedia, Vol. 2017.

Firestein, S., 2001. How the olfactory system makes sense of scents. Nature 413, 211-218.

Freedman, P.H., 2007. In: Food: The History of Taste, Vol. 21. University of California Press, Berkeley, Los Angeles.

Gilbert, A.N., 2008. What the nose knows: The science of scent in everyday life. Crown Publishers, New York. 
Gold, J.I., Shadlen, M.N., 2007. The neural basis of decision making. Annual Review of Neuroscience 30, 535-574.

Gopnik, B., 2012. Aesthetic science and artistic knowledge. Aesthetic Science. Connecting Minds, Brains, and Experience 129-159.

Hekkert, P., Van Wieringen, P.C., 1996. Beauty in the eye of expert and nonexpert beholders: A study in the appraisal of art. The American Journal of Psychology 109, 389-407.

Herman, B., 2013. Scent and Subversion: Decoding a century of provocative perfume. Lyons Press, Guilford, Conneticut.

Herz, R.S., von Clef, J., 2001. The influence of verbal labeling on the perception of odors: Evidence for olfactory illusions?. Perception 30, 381-391.

Hummel, T., Welge-Luessen, A., 2006. Assessment of olfactory function. In: Taste and smell, Vol. 63. Karger Publishers, pp. 84-98.

Jellinek, P., 1997. The psychological basis of perfumery, 4 ed. Blackie Academic and Professional, Chapman \& Hall, London.

Kant, I., 2006 [1798]. Anthropology from a pragmatic point of view. Cambridge University Press, Cambridge.

Keller, A., 2017a. The distinction between perception and judgment, if there is one, is not clear and intuitive. Behavioral and Brain Sciences 39, e249.

Keller, A., 2017b. Philosophy of olfactory perception. Springer, Palgrave Macmillan.

Keller, A., Vosshall, L.B., 2004. Human olfactory psychophysics. Current Biology 14, R875-R878.

Keller, A., Vosshall, L.B., 2008. Better smelling through genetics: Mammalian odor perception. Current Opinion in Neurobiology 18, 364-369.

Keller, A., Vosshall, L.B., 2016. Olfactory perception of chemically diverse molecules. BMC Neuroscience 17, 55.

Livingstone, M., 2002. Vision and Art: The Biology of Seeing. Harry N. Abrams, New York.

Macpherson, F., 2012. Cognitive penetration of colour experience: Rethinking the issue in light of an indirect mechanism. Philosophy and Phenomenological Research 84, 24-62.

Majid, A., 2016. What other cultures can tell us about the sense of smell. In: Tinguely, M. (Ed.), Belle haleine - the scent of art: Interdisciplinary symposium. Kehrer, Heidelberg, pp. 72-77.

Mandoki, K., 2007. Everyday aesthetics: Prosaics, the play of culture and social identities. Ashgate Publishing, Ltd.

Mandoki, K., 2015. The indispensable excess of the aesthetic: Evolution of sensibility in nature. Lexington Books.

Marin, M.M., 2015. Crossing boundaries: Toward a general model of neuroaesthetics. Frontiers in Human Neuroscience 9.

Melcher, J.M., Schooler, J.W., 1996. The misremembrance of wines past: Verbal and perceptual expertise differentially mediate verbal overshadowing of taste memory. Journal of Memory and Language 35, 231-245.

Ohloff, G., Pickenhagen, W., Kraft, P., 2011. Scent and chemistry. The molecular world of odors. Wiley-VCH.
Ramachandran, V.S., Hirstein, W., 1999. The science of art: A neurological theory of aesthetic experience. Journal of Consciousness Studies 6, 15-51.

Royet, J.-P., Plailly, J., Saive, A.-L., Veyrac, A., Delon-Martin, C., 2013. The impact of expertise in olfaction.

Saito, Y., 2015. Aesthetics of the everyday. In: In: Zalta, E.N. (Ed.), Stanford encyclopedia of philosophy, Vol. 2016.

Shadlen, M.N., Kiani, R., 2013. Decision making as a window on cognition. Neuron $80,791-806$.

Shapin, S., 2012. The tastes of Wine: Towards a cultural history. Rivista di estetica $51,49-94$.

Shepherd, G.M., 2004. The Human Sense of Smell: Are We Better Than We Think?. PLOS Biology 2, e146.

Shepherd, G.M., 2006. Smell images and the flavour system in the human brain. Nature 444, 316-321.

Shepherd, G.M., 2012. Neurogastronomy: How the brain creates flavor and why it matters. Columbia University Press, New York.

Smith, B.C., 2007a. The objectivity of taste and tasting. In: Smith, B. (Ed.), Questions odf Taste: The Philosophy of Wine. Oxford University Press, USA, New York, pp. 41-78.

Smith, B.C., 2007b. Questions of Taste: The philosophy of Wine. Oxford University Press, USA, New York.

Spence, C., Piqueras-Fiszman, B., 2014. The perfect meal: The multisensory science of food and dining. John Wiley \& Sons.

Todd, C., 2010. The philosophy of wine. McGill-Queen's University Press, Montreal and Kingston.

Walton, K.L., 1970. Categories of art. The Philosophical Review 79, 334-367.

Wise, P.M., Olsson, M.J., Cain, W.S., 2000. Quantification of odor quality. Chemical Senses 25, 429-443.

Wnuk, E., Majid, A., 2014. Revisiting the limits of language: The odor lexicon of Maniq. Cognition 131, 125-138.

Xenakis, I., Arnellos, A., 2014. Aesthetic perception and its minimal content: A naturalistic perspective. Frontiers in Psychology 5.

Zaidel, D.W., 2015. Neuroesthetics is not just about art. Frontiers in Human Neuroscience 9 .

Zarzo, M., Stanton, D.T., 2009. Understanding the underlying dimensions in perfumers' odor perception space as a basis for developing meaningful odor maps. Attention, Perception, \& Psychophysics 71, 225-247.

Zeki, S., Nash, J., 1999. Inner Vision: An exploration of art and the brain, Vol. 415. Oxford University Press, Oxford.

Zelano, C., Mohanty, A., Gottfried, J.A., 2011. Olfactory predictive codes and stimulus templates in piriform cortex. Neuron 72, 178-187.

Zellner, D.A., Kautz, M.A., 1990. Color affects perceived odor intensity. Journal of Experimental Psychology: Human Perception and Performance 16, 391.

Zucco, G.M., Carassai, A., Baroni, M.R., Stevenson, R.J., 2011. Labeling, identification, and recognition of wine-relevant odorants in expert sommeliers, intermediates, and untrained wine drinkers. Perception 40, 598-607. 